\title{
Electron Microscope Observations of Rhizopus rhizopodiformis
}

\author{
BY H. J. WERNER, P. WRIGHT AND R. D. BAKER \\ Department of Zoology, Louisiana State University, \\ Baton Rouge, Louisiana, U.S.A.
}

(Received 29 May 1964)

\begin{abstract}
SUMMARY
The fine structure of Rhizopus rhizopodiformis was investigated. Other than a slightly modified potassium permanganate fixative, routine techniques of electron microscopy were used. The walls of the hyphae were fibrillar and electron dense. A plasmalemma, perhaps double in nature, was present. Yet to be interpreted membrane-bound vesicles were located uniformly just inside the plasmalemma. Classical ubiquitous mitochondria and smooth-surfaced endoplasmic reticulum were visible. Two inclusions, lipid and glycogen, were present. The hyphae were frequently multi-nucleated. The nuclear walls were doubled, porous, and connected with the endoplasmic reticulum.
\end{abstract}

\section{INTRODUCTION}

No account of the fine structure of Rhizopus rhizopodiformis has yet been published. Hawker \& Abbott (1963) have made a study of the fine structure of the hyphae of $\boldsymbol{R}$. homothallicus and $\boldsymbol{R}$. sexualis. Several apparent differences seem to exist in these rather closely related forms and as such merit mention.

\section{METHODS}

Mycelia from a stock culture of Rhizopus rhizopodiformis were cultured in the following medium (g./1.): Phytone (Baltimore Biological Laboratories, Baltimore 18, Maryland, U.S.A.) 10.0, glucose 10.0, agar 15.5, cycloheximide $0 \cdot 4$, and chloramphemical $0 \cdot 05$. Cultures were incubated in the dark at $29^{\circ}$ for $24 \mathrm{hr}$. Young hyphae were fixed in a $1 \%$ unbuffered solution of potassium permanganate. To facilitate penetration, three drops of a $1 \%$ solution of sodium alkane sulphonate (no. 411 ; Esso Research and Engineering Company, Linden, La., U.S.A.) were added to each $50 \mathrm{ml}$. of potassium permanganate. All fixed hyphae were subsequently rinsed in distilled water and then dehydrated as recommended by Spurlock, Kattine \& Freeman (1963). Embedding was carried out in Maraglas (Freeman \& Spurlock, 1962). Polymerization was done at $60^{\circ}$ for $48-60 \mathrm{hr}$. Sections were cut with a DuPont diamond knife and stained with lead hydroxide as suggested by Millonig (1961). Photographs were taken with an R.C.A. EMU-3F electron microscope.

\section{OBSERVATIONS}

The cell walls of Rhizopus rhizopodiformis are quite similar to those of Neurospora crassa as described by Shatkin \& Tatum (1959) and also similar to those of R. homothallicus as described by Hawker \& Abbott (1963). The cell walls were 
uniformly electron-dense structures distinctly fibrillar in nature (Pl. 1, fig. 1). A very delicate plasmalemma was detectable just inside the cell wall. There are suggestions that it was a double structure (Pl. 1, fig. 1). Of special interest were the constantly occurring, uniformly arranged, definite membrane-bound vesicles situated just inside of the plasmalemma. Occasionally, these vesicles showed additional internal organization (Pl. 1, fig. 1). With the evidence on hand, we are not in a position firmly to interpret these structures. The consensus is that these membrane-bound vesicles were a typical manifestation of pinocytosis. Despite the fact that young hyphae were used, we were never able to detect the cortical membrane described by Hawker \& Abbot (1963) nor the lomosomes of Moore \& McAlear (1961). We cannot confirm the observation that mitochondria display a type of polarity in that these organoids exhibit a predilection for the cortical areas of the hyphae. In $R$. rhizopodiformis the opposite prevailed-the mitochondria were ubiquitous in distribution. Mitochondria were classical in appearance with double membranes and internal cristae arranged often times in parallel plates (Pl. 1, fig. 2). The endoplasmic reticulum, devoid of attached RNA, showed smooth profiles. It ramified haphazardly throughout the cell. This system consisted principally of narrow flattened tubules and, not too infrequently, the endoplasmic reticulum assumed the form of irregular cisternae (P1. 2, fig. 3). The contents of the cisternae were invariably less electron dense than that of the adjacent cytoplasm. Suggestions of continuity of the endoplasmic reticulum membrane were encountered (Pl. 2, fig. 4). Two inclusions were demonstrable in the cytoplasm: lipids and glycogen (P1. 1, fig. 2; Pl. 2, figs. 3, 4). With potassium permanganate preparations, the lipids appeared as completely empty vesicles. These vesicles had characteristically distinct electron-dense membrane boundaries. Particulate clumped areas in the cytoplasm with a basophilia of varying intensity, but always greater than that of the basic granularity of the cytoplasm, were considered to be glycogen. Their size, basophilia, and general appearance agreed with the description of glycogen by Revel, Napolitano \& Fawcett (1960). The hyphae of $R$. rhizopodiformis were frequently bi- and multi-nucleated (Pl. 1, figs. 1, 2). The nuclei showed considerable variation in electron density. The nuclear membrane had a typical double membrane structure. Pores were present in the wall at irregular intervals (Pl. 1, fig. 2).

This investigation was supported by Grants HE. 2549 and AI 04546-03 through the Department of Pathology, L.S.U. School of Medicine, New Orleans, La., U.S.A., and The University Council on Research.

\section{REFERENCES}

Freeman, J. A. \& Spurlock, B. O. (1962). A new epoxy embedment for electron microscopy. J. Cell Biol. 3, 437.

Hawker, L. E. \& Aввот, P. McV. (1963). Fine structures of vegetative hyphae of Rhizopus, J. gen. Microbiol. 30, 401.

Mrluonig, G. (1961). A modified procedure for lead staining of thin sections. J. biophys. biochem. Cytol. 11, 736.

Moore, R. T. \& McAlxar, J. H. (1961). Fine structure of Mycota. Lomosomespreviously uncharacterized hyphal structures. Mycologia, 53, 194.

Revel, J. P., Napolitano, L. \& Fawcett, D. W. (1960). Identification of glycogen in electron micrographs of thin tissue sections. J. biophys. biochem. Cytol. 8, 575. 

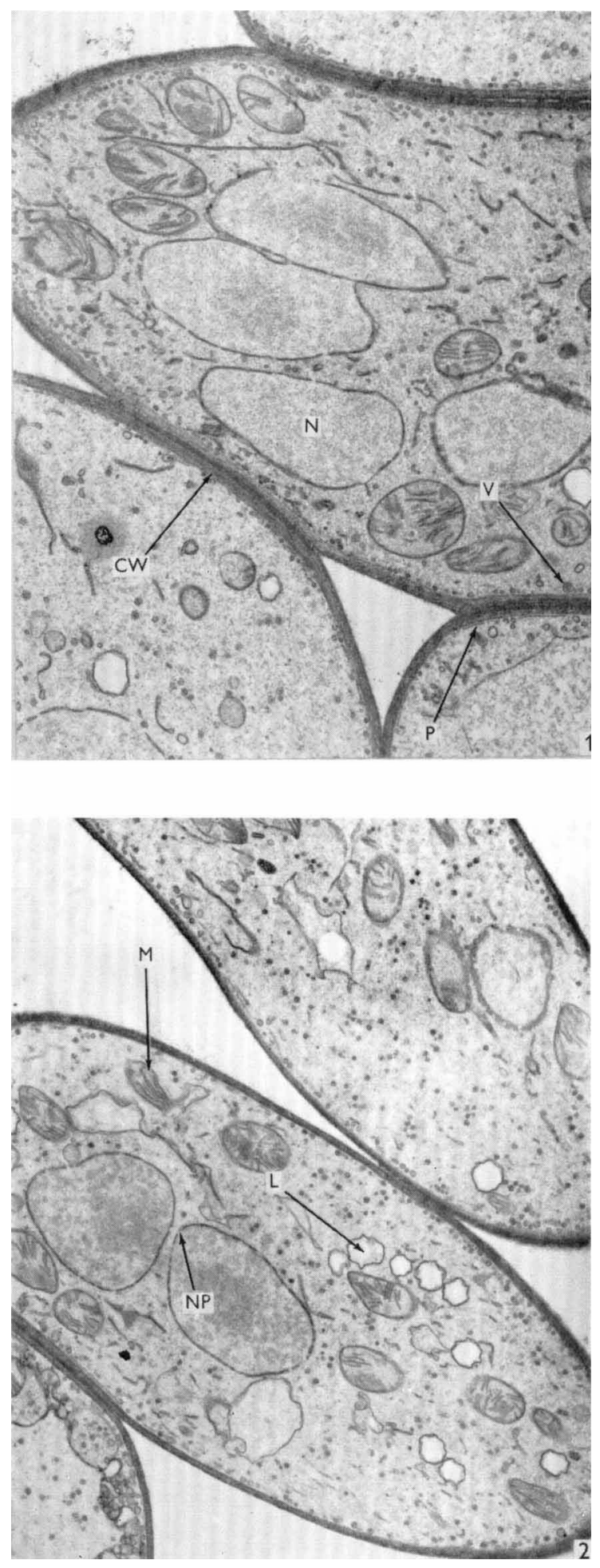

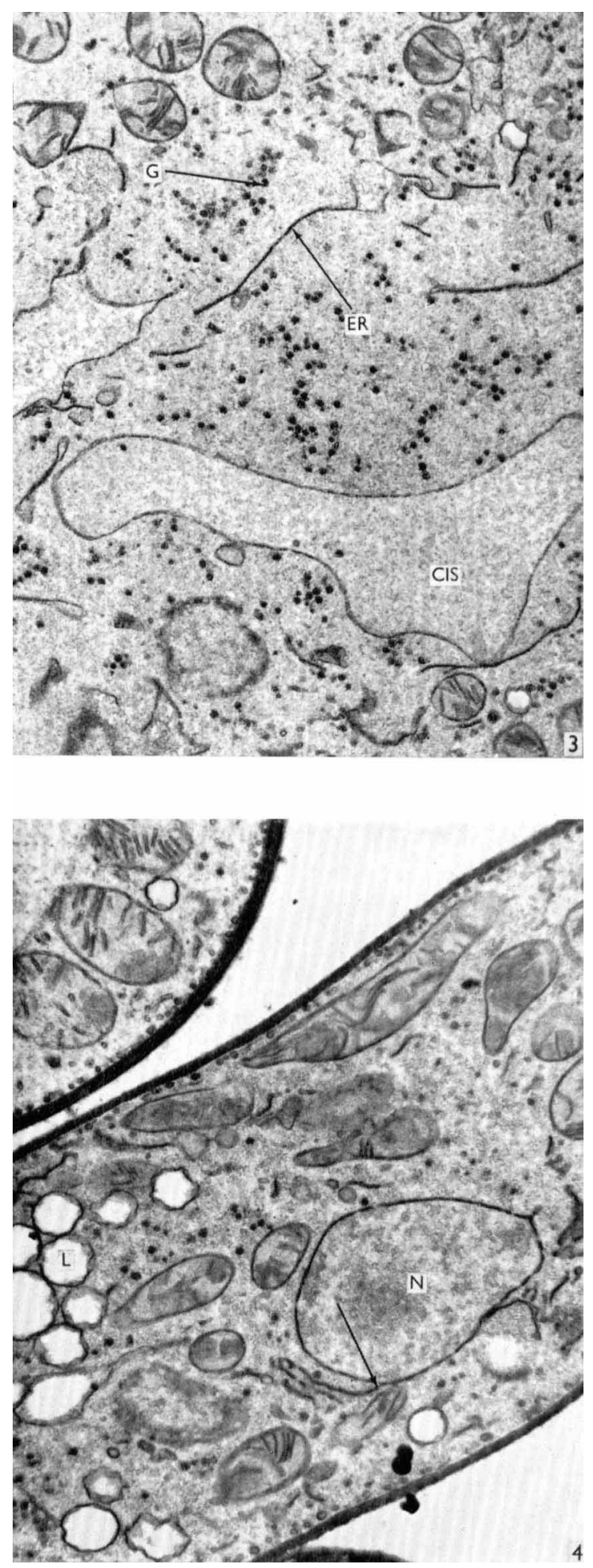

H. J. WERNER, P. WRIGHT AND R. D. BAKER 
Shatkin, A. J. \& Tatum, E. L. (1959). Electron microscopy of Neurospora crassa mycelia. J. biophys. biochem. Cytol. 6, 423.

Spurlock, B. O., Kattine, V. \& Freeman, J. A. (1963). Technical modifications in Maraglas embedding. J. Cell Biol. 17, 203.

\section{EXPLANATION OF PLATES}

\section{Plate 1}

Fig. 1. Sections of Rhizopus rhizopodiformis showing fibrillar wall, plasmalemma, multinucleated condition, and membrane-bound vesicles. $\times 24,000$.

Fig. 2. Section of $\boldsymbol{R}$. rhizopodiformis showing nuclear pores, mitochondria with parallel cristae, and lipid inclusions. $\times 24,000$.

Plate 2

Fig. 3. Section of $\boldsymbol{R}$. rhizopodiformis showing glycogen and the flattened and cisternal varieties of the endoplasmic reticulum. $\times 33,000$.

Fig. 4. Section of $R$. rhizopodiformis showing a connexion of the endoplasmic reticulum with the nucleus. $\times 24,000$.

$\begin{aligned} \text { CW } & \text { cell wall } \\ \mathbf{N} & \text { nucleus } \\ \mathbf{V} & \text { vesicle } \\ \mathbf{P} & \text { plasmalemma } \\ \mathbf{G} & \text { glycogen }\end{aligned}$

\section{Abbreviations}

ER endoplasmic reticulum

Cis cisternae

M mitochondrion

L lipid

NP nuclear pore 